\title{
How Porosity Increases During Incipient Weathering of Crystalline Silicate Rocks
}

\author{
Alexis Navarre-Sitchler \\ Department of Geology and Geological Engineering \\ and \\ Hydrologic Sciences and Engineering Program \\ Colorado School of Mines \\ Golden, Colorado 80401, USA \\ asitchle@mines.edu \\ Susan L. Brantley \\ Earth and Environmental Systems Institute \\ and \\ Department of Geosciences \\ The Pennsylvania State University \\ University Park, Pennsylvania, USA \\ brantley@essc.psu.edu

\section{Gernot Rother} \\ Chemical Sciences Division \\ Oak Ridge National Laboratory \\ Oak Ridge, Tennessee, USA \\ rotherg@ornl.gov
}

\section{INTRODUCTION}

Weathering of bedrock to produce porous regolith, the precursor to biologically active soil and soluble mineral nutrients, creates the life-supporting matrix upon which Earth's Critical Zone-the thin surface layer where rock meets life-develops (Ollier 1985; Graham et al. 1994; Taylor and Eggleston 2001). Water and nutrients locked up in low porosity bedrock are biologically inaccessible until weathering helps transform the inert rock into a rich habitat for biological activity. Weathering increases the water-holding capacity and nutrient accessibility of rock and regolith by increasing porosity and mineral surface area, affecting the particle-size distribution, and enhancing ecosystem diversity (Cousin et al. 2003; Certini et al. 2004; Zanner and Graham 2005). Especially in areas where soils are thin and climate is dry, the water stored in weathered rock is essential to ecosystem productivity and survival (Sternberg et al. 1996; Zwieniecki and Newton 1996; Hubbert et al. 2001; Witty et al. 2003). Removal of soluble material during weathering decreases the concentrations of major elements such as $\mathrm{Ca}, \mathrm{Na}$, and $\mathrm{Mg}$ and the overall mass of the solid, decreasing the bulk density and increasing porosity. These chemical and physical changes result in decreased uniaxial compressive strength and elastic moduli of the rock and increased infiltration of water through the weathered rock (Tugrul 2004).

Porosity in intact bedrock is comprised of inter- and intra-granular pores developed during (re-) crystallization in igneous and metamorphic rocks or diagenesis in sedimentary rocks. As 
we conceptualize it, the conversion of low-permeability bedrock to regolith generally begins due to the transport of meteoric water into protolith through the large-scale fractures that are present as a result of regional tectonic factors or exhumation (Wyrick and Borchers 1981; Molnar et al. 2007). In zones near the fractures, water can infiltrate into the low-porosity rock matrix. This infiltrating meteoric water contains dissolved oxygen and is acidified by $\mathrm{CO}_{2}$ and organic acids, promoting chemical reactions with primary minerals in the rock (e.g., feldspars, pyroxenes, and micas). This ultimately leads to increased porosity through mineral dissolution and weathering-induced fracturing (WIF).

As weathering increases both matrix and fracture porosity, more water can infiltrate the rock, leading to more weathering in a positive feedback loop that drives long-term regolith production. Dissolution and fracturing lead eventually to disaggregation of the rock. In this respect, weathering of primary minerals can be an autocatalytic reaction, as described previously (Brantley et al. 2008). Here, the reaction product of the autocatalytic reaction that accelerates the reaction rate is the surface area of the reacting mineral, which increases due to opening of internal porosity to meteoric water infiltration, roughening of the surface, or WIF. Of course, weathering also promotes precipitation of secondary minerals that can occlude porosity and armor dissolving grains. Eventually, the dissolution of the primary mineral grains cannot be compensated by increases in wetted surface area, and the overall surface area of dissolving primary minerals decreases.

A long history of geochemical research has helped elucidate the macroscale behavior of weathering processes, including quantification of rock weathering rates and soil production and factors that influence these rates (e.g., Merrill 1906; Berner 1978; Pavich 1986; Nahon 1991; Blum et al. 1994; Drever and Clow 1995; Clow and Drever 1996; Anderson et al. 2002, 2011; Gaillardet et al. 2003; Amundson 2004; Bricker et al. 2004; Burke et al. 2007; White 2008; Brantley and Lebedeva 2011; Hausrath et al. 2011). However, until recently the very earliest pore-scale physical changes associated with incipient weathering were largely unstudied. Recent evidence shows how weathering begins the evolution of porosity by affecting even the smallest pores (pores with diameters $<100 \mathrm{~nm}$ ) in crystalline igneous rocks (Navarre-Sitchler et al. 2009). Ultimately, feedback between weathering and porosity creation transforms bedrock to regolith. A better understanding of these pore-scale changes that occur in rock during incipient weathering will help link micro-scale behavior and processes to those that can be observed and predicted in numerical simulation of macro-scale changes (e.g., Kang et al. 2007; Li et al. 2008; Jamtveit and Hammer 2012; Molins et al. 2012; Emmanuel et al. 2015, this volume; Molins 2015, this volume).

For example, in a meta-analysis of data in the literature, Bazilevskaya et al. (2013) concluded that regolith on granitic rocks worldwide tends to be thicker than on basaltic rock compositions when measured at ridgetops under similar climate regimes (Fig. 1). These differences have been attributed to lithological controls on WIF, which can ultimately open a rock to deep infiltration of meteoric water. Simple modeling exercises document that the depth interval over which a mineral reacts from parent concentration to $0 \%$ - the reaction front-is wider and the depth of regolith itself is thicker for a rock where advection contributes to solute transport as opposed to one where solute transport occurs only by diffusion (Brantley and Lebedeva 2011; Bazilevskaya et al. 2013). Specifically, Bazilevskaya et al. (2013) argued that larger volumes of weathering fluids infiltrate granitic rocks than basaltic rocks because WIF occurs when biotite in granites oxidizes at depth. In this article we review studies of porosity development during incipient weathering of igneous rocks - the rock type in which the bulk of this type of research has been performed to date and we explore the presence or absence of WIF in this context. Throughout the next sections we discuss aspects of the pore network, such as pore-size distribution, connectivity, and pore morphology as they have been quantified or observed at nanometer to micron length scales. For simplicity, we refer to 


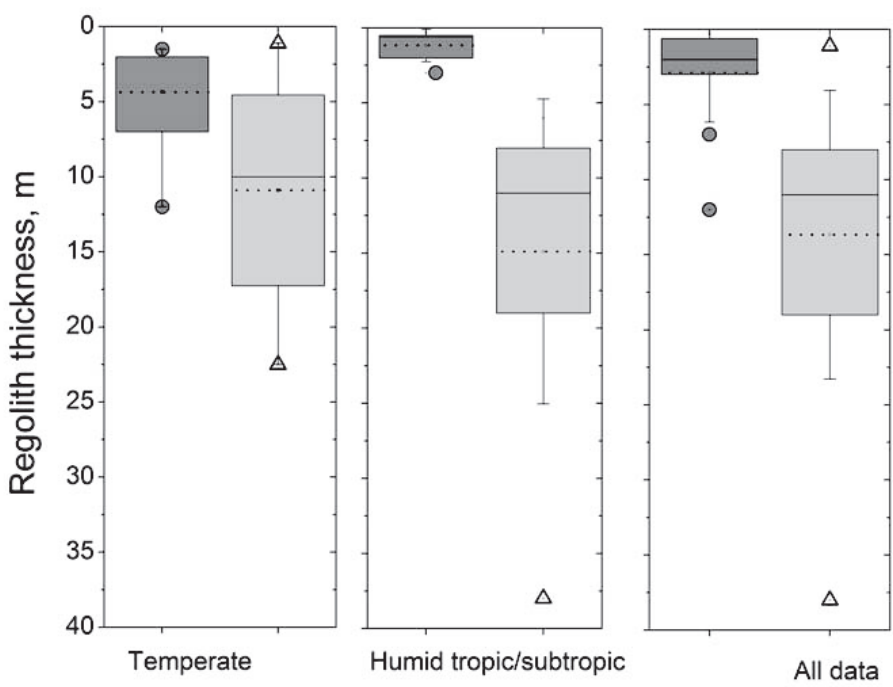

Figure 1. Regolith thickness shown in box and whisker plots for mafic rocks (14, dark boxes) versus granitic material (13, light boxes) from ridgetop systems reported in the literature and summarized by Bazilevskaya et al. (2013) for different climate regimes as indicated (all systems had precipitation $>$ potential evapotranspiration). Each box represents the envelope for $50 \%$ of the reported measurements. The median is shown as the solid line and the mean as the dotted line in each box. Whiskers show one standard deviation. Outliers are shown as symbols. [Used by permission of John Wiley \& Sons, Ltd. from Bazilevskaya EA, Lebedeva M, Pavich M, Rother G, Parkinson D, Cole DR, Brantley SL (2013) Where fast weathering creates thin regolith and slow weathering creates thick regolith. Earth Surface Processes and Landforms, Vol. 38, Fig 1, p. 848.]

these porosities as nanoporosity and microporosity, respectively. Although this terminology is loose, it is operationally useful because different techniques are used in the measurement of the differently sized pores, as discussed below. The International Union of Pure and Applied Chemistry (IUPAC) defines micropores as pores with width smaller than $2 \mathrm{~nm}$, mesopores have pore widths of 2-50 nm, and macropores have widths larger than $50 \mathrm{~nm}$ (Sing et al. 1985; Rouquerol et al. 1994).

\section{METHODS FOR POROSITY AND PORE-SIZE DISTRIBUTION QUANTIFICATION}

Detailed analysis and characterization of natural pore systems requires a multitude of techniques that are capable of interrogating different aspects of the pore network across many orders of magnitude length scale. Some of the most widely used techniques include gas sorption, fluid intrusion (including mercury porosimetry), various microscopy and image analysis approaches, and X-ray and neutron scattering.

\section{Sorption and intrusion techniques}

Gas sorption techniques, especially nitrogen sorption measurements at $77 \mathrm{~K}$, are routinely used for the measurement of internal surface area and pore size in the region of 2-200 nm. Nitrogen gas sorption analysis (often referred to as BET analysis) of an intact sample yields the internal surface area and pore size distribution of accessible, connected pore spaces, while analysis of finely powdered samples yields the total porosity and surface area, plus the surface 
area produced by grinding (Brunauer et al. 1938). Analysis of sorption isotherms with density functional theory (DFT) methods yields the most accurate information about the pore size distribution, because it considers the molecular structure of the absorbate (Thommes and Cychosz 2014). However, several important uncertainties often arise during the interpretation of nitrogen sorption data even using advanced DFT techniques. It is often difficult to differentiate between pore adsorption and pore surface roughness using BET data, limiting the utility of the technique for the study of very fine pores (Thommes and Cychosz 2014). Uncertainties in calculated pore size distributions arise from heterogeneity in mineral identity and organic materials in the rock that possess component-specific interaction potentials and wetting properties for nitrogen and an implicit assumption of exclusively cylindrical or slit pore geometries. Thus, the model-dependent analysis of the adsorption isotherm may yield a distorted pore size distribution. Nitrogen sorption analysis often relies on the evaluation of the desorption branch to eliminate pore geometry effects on pore size distribution. However several possible hysteresis effects can obscure the pore size distributions obtained from both the adsorption and desorption branches of the isotherms (Lowell et al. 2004; Thommes and Cychosz 2014). Current research of fluid adsorption and pore condensation to well-defined synthetic mesoporous materials aims at understanding and quantitative description of these effects. Decoupling of the pore shape and confinement effects of the porous medium is possible, for example, using the hydraulic pore radius, $r_{h}$, for the characterization of pore size. The hydraulic pore radius is defined as

$$
r_{h}=\frac{2 V_{p}}{A_{s}},
$$

with $V_{p}$ the pore volume and $A_{s}$ the specific surface area, and describes confinement effects independent of pore geometry. For cylindrical pores, pore radius and hydraulic pore radius are identical, while for slit pores the hydraulic radius equals two times the pore width (Rother et al. 2004; Woywod et al. 2005). The hydraulic pore radius allows characterization of irregularly shaped pore systems. However, this model has not yet been extended to eliminate pore geometry effects on the pore size distribution obtained from gas adsorption measurements.

Mercury porosimetry is a complementary technique to nitrogen sorption, yielding information about the sizes and size distributions of pore throats and associated pore volumes at length scales from ca. $2 \mathrm{~nm}$ to $200 \mu \mathrm{m}$. Mercury porosimetry relies on the forced intrusion of liquid mercury into the pore spaces. The high surface tension of mercury of ca. $486 \mathrm{mN} / \mathrm{m}$ leads to wetting angles between $90^{\circ}$ and $180^{\circ}$, i.e., partial wetting of non-reactive surfaces is found. Therefore, mercury intrudes the larger pores and pore throats at lower pressure, and fills pores of decreasing size with increasing pressure. The Washburn equation gives the relationship between the pressure $P$ and the pore size $r$ into which mercury will intrude:

$$
\operatorname{Pr}=-2 \gamma \cos \theta,
$$

with $\gamma$ the surface tension, and $\theta$ the wetting angle. Commonly, wetting angles of ca. $130-160^{\circ}$ are found for mercury at mineral surfaces. The mercury intrusion curve is commonly not reversible, and uncertainties about the results can arise with respect to possible damages to the sample imposed by the high pressures of up to several kbar involved in the process. A comprehensive review of sorption and intrusion techniques for the characterization of porous solids with numerous examples is given in (Lowell et al. 2004).

\section{Electron and optical microscopy}

Electron and optical microscopy are important tools for the determination of pore shapes and their associations with individual mineral phases. Electron micrographs provide direct information about pore shapes and orientations in 2-D for traditional imaging and 3-D for imaging combined with focused ion beam (FIB) slice and view techniques. However, these 
techniques sample only small volumes. Considering the strong spatial heterogeneities typically found in natural rocks, this is a severe limitation that significantly reduces the statistical relevance of the results. Combined spectroscopic imaging techniques provide unique local structural and chemical information that cannot be obtained otherwise. Electron imaging paired with energy dispersive spectroscopy (EDS) mineral mapping and tomography techniques provide a powerful tool to identify exposed mineral surfaces in pores and correlate pore types with mineralogy as demonstrated by Landrot et al. (2012). While X-ray and neutron tomography methods image 3 -D volumes of rock and partially overcome sample size limitations of electron imaging, the datasets are at micron to millimeter length-scale resolution and thus do not capture nanometer scale details of the pore network. A complement to imaging techniques, neutron scattering is uniquely suited to characterize pore size distributions and surface roughness at length scales from single nanometers to 10's of microns (Anovitz and Cole 2015, this volume). An advantage of neutron scattering techniques over many others is the ability to interrogate both the connected and unconnected fractions of the pore network without physical destruction of the sample. Ultimately, each of these techniques has its unique mix of strengths and limitations, and quite often only the combined use of several techniques allows a detailed and informed analysis. In the following section we will focus on the utility of neutron scattering techniques in the context of rock porosity characterization. Emphasis will be put on the utility of small-angle and ultra- small-angle neutron scattering (SANS and USANS) to comprehensively quantify the nano- to micrometer porosity and surface area, both of which control the initial stages of rock weathering.

\section{Neutron scattering}

Jin et al. (2011) were the first to use neutron scattering to show that the fraction of nanoporosity increases within a rock undergoing weathering. A small-angle neutron scattering experiment is carried out by measuring the scattering signal from a target sample illuminated by a collimated neutron beam with known wavelength, defined beam geometry, and calibrated neutron flux. The majority of neutrons are transmitted through the sample with no interactions, making neutron scattering suitable for the study of much larger samples compared to X-rays. A percentage (up to 10-15\%) are coherently scattered upon interactions with interfaces between regions with contrasts in chemistry and density, resulting in contrasts in scattering length density within the target sample. (Radlinski 2006). The coherent scattering length density $\rho_{\mathrm{j}}{ }^{*}$ (SLD) for a solid phase $j$ is given by Equation (3):

$$
\rho_{j}=\frac{\left(\sum_{i=1}^{n} b_{c i}\right)}{V_{m}} .
$$

Here, $b_{\mathrm{c} i}$ is the bound coherent scattering length of atom $i$ of $n$ atoms of a molecule and $V_{m}$ is the molecular volume $\left(\mathrm{g} \mathrm{mol}^{-1}\right)$. The neutron SLD does not change monotonically with atomic number, and can be very different for different isotopes of the same element. Therefore, neutrons are sensitive to certain light elements, and isotope contrast variation (especially H/D) can be utilized to highlight or suppress certain structural features in neutron scattering. The angle at which the neutrons scatter is a function of the size of the scattering structures, with an inverse relationship between particle size and scattering angle. Typical small-angle neutron scattering (SANS) and ultra- small-angle neutron scattering (USANS) instrument configurations used to study rocks interrogates length scales of approximately $1 \mathrm{~nm}-30 \mu \mathrm{m}$. The intensity of scattered neutrons at each angle is a function of the number of scattering particles and the scattering contrast. Sample sizes of tens to hundreds of $\mathrm{mm}^{3}$ can be efficiently interrogated with neutron scattering methods, making the measurements useful for studies of larger volumes than microscopy methods that give comparable data (e.g., focused ion beam scanning electron microscopy). 
Beam sizes are on the order of 5-200 $\mathrm{mm}^{2}$, and samples can be interrogated with step width on the order of $\mathrm{mm}$. The required sample and beam sizes depend largely on the scattering power of the sample, which is proportional to the difference in the SLD squared of the nanodispersed phases. SLD values of various minerals are generally in the range of $4 \times 10^{10} \mathrm{~cm}^{-2}$, while voids (i.e., empty pores) have a scattering length density of zero. Thus, while neutrons also scatter from mineral grain interfaces, the intensity of scattered neutrons that arises from interfaces between minerals and pores is usually an order of magnitude higher, and rocks can often be treated as a two-phase system when analyzing neutron scattering data, i.e., minerals + pores (e.g., Radlinski 2006; Anovitz et al. 2009; Navarre-Sitchler et al. 2013).

The 2-D pattern of scattered neutrons contains a wealth of information about the internal structure of the sample (Fig. 2). Once corrections are applied for empty beam or cell scattering, transmission and detector efficiency, the 2-D scattering data are analyzed for radial symmetry and averaged to obtain scattered intensity as a function of scattering angle (Fig. 2D). Radially isotropic patterns result from rock samples without preferred orientation of scattering objects, for example, pores in many rock types such as sandstone, limestone, and crystalline igneous rocks. For these rocks, the pore size distribution, internal surface area, and fractal dimensions show no dependence on the sample orientation in the neutron beam. Clays and shales, as well as other rocks with elongated pores with preferential pore orientation, show radial variations in the scattering intensity. Anisotropies of the scattering intensity occur if the sample is oriented in the neutron beam such both the long and the short pore axes are exposed (Fig. 2). These patterns have been explored in more detail in samples of Marcellus shale cut parallel and perpendicular to bedding by Gu et al. (2015).

A unique capability of neutron scattering is its ability to interrogate the entire, undisturbed pore system comprised by both accessible and inaccessible pores and differentiate between the connected and unconnected pore fractions using contrast-matching techniques. In samples saturated with an $\mathrm{H}_{2} \mathrm{O} / \mathrm{D}_{2} \mathrm{O}$ mixture that have the same scattering contrast as the bulk rock, scattering from connected pores is eliminated, with the result that only unconnected pores are sampled (Navarre-Sitchler et al. 2013; Bazilevskaya et al. 2015). Analysis of SANS from dry and contrast-matched water soaked samples then allows for analysis of the properties of connected and unconnected pore fractions. This technique helps delineate the pore-scale changes that result in creation of a connected pore network for fluid infiltration in weathered rocks. Following the evolution of connected and unconnected porosity fractions in rockweathering fronts has provided detailed insight into weathering processes in a number of recent studies (Jin et al. 2011; Bazilevskaya et al. 2013, 2015; Buss et al. 2013; NavarreSitchler et al. 2013; Xin et al. 2015). While neutron scattering is a powerful tool for analysis of rock pore networks, it is best when confirmed and complemented by additional information from sorption studies and detailed electron microscopy (Radlinski et al. 2000, 2004; Kahle et al. 2004; Radlinski 2006; Anovitz et al. 2009, 2013; Jin et al. 2011; Bazilevskaya et al. 2013; Navarre-Sitchler et al. 2013).

The reduction and analysis pathway of neutron scattering data depends on the characteristics of the sample. First, the 2-D detector data are corrected for background and detector sensitivity, and the scattered intensity is normalized to the sample thickness and neutron transmission. Then the intensity is normalized to the empty beam or a calibration standard, and the data are radially averaged, either over the entire detector or azimuthal sections to produce $1 \mathrm{D}$ curves of scattering intensity $I(Q)$ as a function of momentum transfer $(Q)$, which is a function of the scattering angle. Rock nanopores are commonly disordered assemblages of pores with different shapes and sizes, which are partly interconnected. Polydisperse hard sphere models can be applied in that case, which permit calculation of parameters such as pore volume, internal surface area and surface roughness, and the pore size distribution from the scattering data (e.g., Hinde 2004). Particle scattering from pores of 

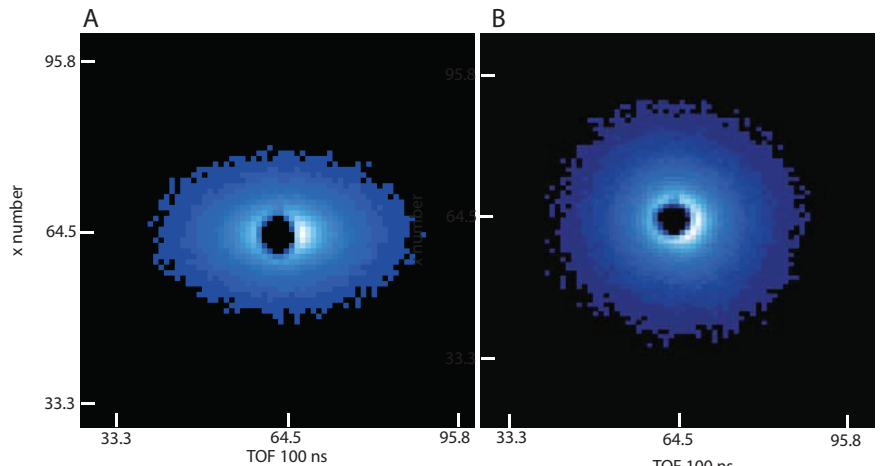

C

D
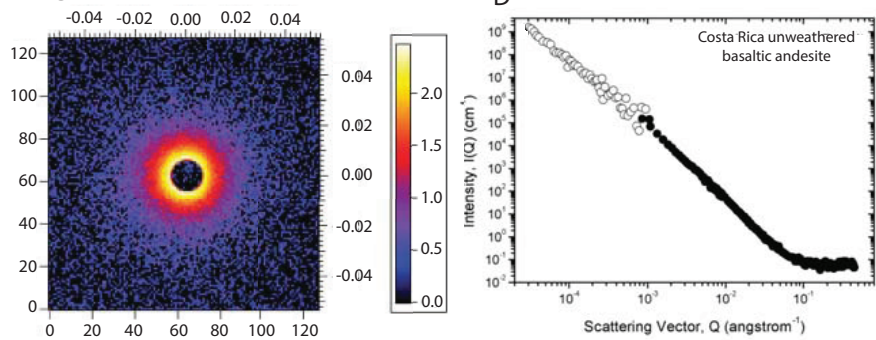

Figure 2. Scattering intensity in 2-D (detector counts shown in color from low in blue to high in white) plotted as $x$-position versus time of flight in 100 s of nanoseconds from a shale sample analyzed at the Lujan Neutron Scattering Center at Los Alamos National Laboratory on a time-of-flight SANS instrument configuration. Data from a sample cut perpendicular to bedding giving an anisotropic scattering pattern that indicates preferentially oriented pores (A). The same sample broken into chips and packed into a cuvette to randomize the pore orientations give an isotropic scattering pattern (B). Scattering data from a thick section of unweathered basaltic andesite from Costa Rica (C) show isotropic scattering from random pore orientations in the rock. Pixel position on the detector ranges from 0 to 120 on $x$ - and $y$-axes. Correlating $Q$ values range from 0.04 to $-0.04 \AA^{-1}$. Scattering intensity is shown from low in black to high in yellow. Isotropic 2-D scattering data are radially averaged to obtain scattering intensity as a function of scattering angle data for analysis. An example of small-angle scattering shown in radially averaged (1D) is from the unweathered core of a basaltic andesite clast from Costa Rica (D). Small-angle neutron scattering data (black circles) are combined with ultra- small-angle neutron scattering data (white circles) to obtain scattering over three orders of magnitude in length scale (from $<10 \mathrm{~nm}$ to $>30 \mathrm{~mm}$ ).

characteristic size $R$ is observed at $Q \approx 2.5 / R$. Surface scattering from these structures is found at $Q>1 / R$, which can be delineated from particle scattering to assess surface roughness associations with pore size. In many rocks and soils, pore sizes span several orders of magnitude, and scattering data can often be modeled using fractal models. Fractal dimensions and their associated size ranges can give important statistical insight into the morphological properties of rock porosity and its changes with reaction progress. As described in the next section, the surface or mass fractal dimensions of the rock can be directly obtained from the slope of the scattering curves in the applicable range of momentum transfers (Teixeira 1988).

\section{Fractal nature of rocks}

As shown by neutron scattering analysis, the pore size distribution in many rocks can be described by a mass fractal (Radlinski et al. 2000; Anovitz et al. 2009). Similarly, the roughness of internal pores and cracks often shows surface fractal behavior. Specifically, for 
many rocks, the intensity $(I)$ of scattered neutrons is observed to be inversely proportional to $Q^{m}$ over extended regions in $Q$, where $m$ is termed the Porod exponent:

$$
I(Q)=\frac{A}{Q^{m}}+B
$$

Here $B$ is the background, observed to be independent of scattering vector. The background arises typically from incoherent scattering from scatterers such as hydrogen nuclei or smallscale nuclear density inhomogeneities (Radlinski 2006). This background scattering, which may lead to a constant scattering intensity at large $Q$, does not contain structural information, and is usually subtracted following standard procedures.

When a plot of $\log I$ versus $\log Q$ is linear over more than one order of magnitude of $Q$, the object causing scattering is considered a fractal where the slope, $-n$, is related to the fractal dimension. Research during the 1980s and 1990s showed that unweathered shale, sandstone, and igneous rocks can yield plots of $\log I-\log Q$ that are linear over several orders of magnitude (Mildner et al. 1986; Aharonov and Rothman 1996; Radlinski et al. 1999). In fact, in the case of shales these plots can be linear over ten orders of magnitude (Jin et al. 2013).

Unweathered rocks can show evidence of both mass and surface fractals. A value of $n$ between 2 and 3 indicates presence of a mass fractal. In this case, the mass fractal dimension, $D_{m}$, is equivalent to the value of $n$. In contrast, a value of $n$ between 3 and 4 characterizes a surface fractal. In this case the surface fractal dimension $D_{s}$ equals $(6-n)$. These relationships, which have been discussed by many authors (Mildner et al. 1986; Wong and Bray 1988; Schmidt 1991; Radlinski 2006), allow straightforward classification of the multi-scale, complex disordered pore systems found in rocks. Interpretation of the obtained fractal dimensions relies on the concepts developed in fractal systems analysis. One definition of a surface fractal is that it is an object of dimension $L$ with a surface area that varies as $L^{D_{s}}$, where $D_{s}$ lies between 2 and 3 but is non-integral. Similarly, a mass fractal has a mass that varies as $L^{D_{m}}$, where $D_{m}$ lies between 2 and 3, and is non-integral (Radlinski 2006). As the fractal dimension of an object approaches a value of 3 , the object becomes either more space-filling (surface fractal) or more polydisperse (mass fractal).

In weathering rocks, neutrons scatter from pores and bumps on surfaces that vary in dimension from nanometers to tens of microns. In the simplest case, the internal porosity of the unweathered rock comprises only one fractal. For example, in both the Rose Hill shale (Jin and Brantley 2011) and Marcellus shale (Jin et al. 2013) sampled from central Pennsylvania (U.S.A.), neutron scattering reveals that the internal porosity is a fractal with dimension near 3. However, for crystalline rocks, the parent material is often comprised of two fractals, i.e., both a mass and surface fractal. For example, internal porosity has been characterized by neutron scattering as a mass plus surface fractal for the following crystalline rock protoliths: Costa Rica andesitic basalt (Navarre-Sitchler et al. 2013), Virginia diabase (Bazilevskaya et al. 2013, 2015), Puerto Rico quartz diorite (Navarre-Sitchler et al. 2013), Puerto Rico volcaniclastic sedimentary rock (Buss et al. 2013), and Virginia metagranite (Bazilevskaya et al. 2013, 2015). These rock systems are described in more detail in the next sections. In each case, the authors have argued that the mass fractal at low $Q$ can be conceptualized as an object comprised of pores ranging in size from hundreds of nanometers to tens of microns. These pores are likely positioned mostly at grain boundaries and triple junctions. In contrast, the surface fractal found at large $Q$ is the distribution of smaller scatterers ( 1 to $300 \mathrm{~nm}$ ) that can be conceptualized as bumps on the pore surfaces. Obviously, some spatial dimension describes the point where bumps grade into pores: in fact, the break in slope on the $\log I-\log Q$ curve (the size delineation between the mass and surface fractal) varies from rock to rock, but generally is related to the average grain size (Radlinski 2006). 


\section{CASE STUDIES}

Studies of incipient nano- and microporosity development during terrestrial weathering have spanned various rock lithologies from granitic to ultramafic compositions in igneous rocks to shales in sedimentary rocks. Here we review study results and methods used to quantitatively analyze the development of porosity during the initial stages of weathering of the crystalline igneous rocks with a focus on compositions from granitic to basaltic. We do not review the recent suite of papers that treat carbonation of ultramafic rocks (e.g., Keleman et al. 2011), but rather focus on systems without significant precipitation of carbonate minerals. In the reported case studies, incipient weathering and development of fine-scale porosity has been studied in the context of different spatial scales. For example, incipient weathering has been investigated at the pedon scale by probing the regolith-bedrock interface at the base of undisturbed weathering profiles. On the other hand, it has also been probed at a smaller scale such as the boundary between weathering rinds and unweathered cores of clasts found weathering in alluvial or glacial deposits. This review includes studies at both scales.

At the pedon scale, weathering processes are often studied at ridgetop locations to allow investigators to model the natural processes as one-dimensional systems, i.e., minimizing the influence of lateral fluid flow and sediment translocation that can add material to the top of the profile through downslope transport (e.g., Jin et al. 2010). However, given the small number of studies of incipient porosity development, we do not limit this review to studies of ridgetop locations only. While there are numerous studies of bulk porosity in regolith and soils, to the authors' knowledge the following studies of the initiation of weathering represent the only published papers where total porosity was quantified along with information on the morphology or pore size distribution of the earliest nano- or microporosity created. We limited our review to these studies for the purpose of gaining insight into the physical changes that occur in rocks during weathering at the pore scale.

In some studies chemical analysis was used to define the degree of weathering of each sample. In others, more descriptive means were used to define the extent of weathering. Thus, it is not possible to link the degree of porosity development directly to the degree of chemical weathering for all the studies. Nonetheless, the thickness and advance rate of weathering profiles on unweathered bedrock are highly dependent on the rates of mineral weathering and the flux of water through the weathering front and some generalizations can be made (Lichtner 1988; White 2002). Laboratory-measured mineral dissolution rates of minerals common in basaltic and andesitic rocks (Ca-rich plagioclase, augite, and actinolite for example) are generally faster than those common in the more felsic granite and granodiorite rocks (quartz, Na-rich feldspar, and alkali feldspar). Related to this, regolith on more felsic rocks tends to be thicker than regolith developed on more mafic rocks (Fig. 1). To explore these observations we have separated the case studies into felsic and mafic rocks in the next sections.

\section{Weathering of felsic to intermediate composition rocks}

In this section we review porosity changes during incipient weathering on rocks ranging in composition from granites and granodiorites to quartz diorite to diorite. These compositions are globally important: granite and granodiorite are exposed over $\sim 15 \%$ of the global land surface and underlie many mountain watersheds (Twidale and Vidal Romani 2005). Therefore, granitic weathering is also an important sink of atmospheric $\mathrm{CO}_{2}$ ( $\mathrm{Li}$ et al. 2013; Maher and Chamberlain 2014). The more felsic rocks differ during weathering compared to the more mafic rocks discussed in the next section because of the common occurrence of WIF. Our summary of felsic rocks includes weathering reported in seven separate settings.

Rocks of this lithology typically have very low primary porosity (less than a few percent) and correspondingly low permeability, but generally have large-scale fractures and joints related to tectonic processes such as mountain building and exhumation (Twidale and Vidal 
Romani 2005; Molnar et al. 2007). The predominant mineralogy of the rocks described here includes quartz, alkali feldspar, and Na-rich plagioclase feldspar with muscovite and/ or biotite micas. Accessory minerals include hornblende, magnetite, ilmenite, pyrite, sphene, and zircon. Biotite mica is the predominant Fe-bearing mineral in the samples reported here. In the following paragraphs, we summarize each study setting and its weathering and porosity characteristics.

Puerto Rico quartz diorite. A study of samples of quartz diorite from the Luquillo Critical Zone Observatory in the Luquillo Experimental Forest provides the most detailed published information on porosity development during initial weathering of felsic rocks in a setting where many other water and soil fluxes have been measured (Navarre-Sitchler et al. 2013). Navarre-Sitchler et al. investigated an unweathered corestone of quartz diorite, several meters in diameter and surrounded by onionskin-like spheroidal fractures that had been previously described in the literature (Turner et al. 2003). The spheroidal fractures subtend rindlets that are each roughly 2 or $3 \mathrm{~cm}$ in width (Buss et al. 2008). The entire set of rindlets around the corestone is $\sim 40 \mathrm{~cm}$ thick. Samples of rindlets and unweathered corestone were analyzed by SANS and USANS along with transmission electron microscope (TEM) imaging (NavarreSitchler et al. 2013). The low porosity $(<2 \%)$ corestone transforms to saprolite across the rindlet zone, and the concentration of plagioclase decreases from parent values to near zero (where most of the loss is in the outermost rindlets): in other words, the rindlet set comprises the plagioclase reaction front. The individual rindlets are intact but increasingly fractured pieces of rock that are hypothesized to have been created by WIF (Fletcher et al. 2006; Buss et al. 2008). Although bulk density decreases from the corestone outward to the outermost rindlets (Buss et al. 2008), the nanoporosity-i.e., porosity measured by neutron scatteringincreases markedly in the outermost rindlet to 9.4\%. TEM images show microfracture development throughout the rindlet set. These microfractures inside individual rindlets are documented in the neutron scattering data and TEM images at length scales of 60-600 nm, i.e., length scales that are consistent with fracture aperture. The major spheroidal fractures that subtend rindlets have been attributed to volume expansion driven by Fe oxidation during biotite alteration (Fletcher et al. 2006; Buss et al. 2008). Presumably, the microfractures form within individual rindlets both due to WIF as well as relaxation of the rindlets after spheroidal fracture formation.

In the innermost rindlets, nanoporosity increases mostly through microfracturing, with little mass removal though mineral dissolution. Once a connected pore network in a rindlet is established through microfractures, however, primary minerals begin to dissolve and the rock matrix nanoporosity increases to $>9 \%$ in the last $3 \mathrm{~cm}$ of the $40-\mathrm{cm}$ rindlet zone. Analysis of nanopore surface area distribution in the innermost rindlets suggests that the largest surface area increases occurs in pores $\lesssim 50 \mathrm{~nm}$ in the innermost (youngest) rindlets (Navarre-Sitchler et al. 2013). Weathering in the outer rindlets is thought to be enhanced by the presence of Fe-oxidizing organisms that further accelerate weathering by production of organic acids that mobilize Fe and Al.

Virginia Piedmont metagranite. Three recent papers report the growth of porosity during incipient weathering of metagranite at ridgetops in the Virginia Piedmont, U.S.A. (Bazilevskaya et al. 2013, 2015; Brantley et al. 2013b). In that setting, the slow rate of erosion and long timescale of exposure to weathering have allowed the weathered regolith profile to putatively reach a steady-state thickness. The authors point out that both the regolith itself and the plagioclase weathering front are 20-times thicker on the metagranite (a metamorphosed quartz monzonite comprised of quartz, albite, orthoclase, muscovite, and biotite) than on a nearby diabase. The diabase is a basaltic composition rock that is discussed in the next section. A combination of methods was used to probe this difference, including neutron scattering, 
X-ray micro-computed tomography, TEM, SEM, and chemical analysis. Total porosity of the metagranite increased from $\sim 2.5 \%$ in the unweathered samples to a maximum of $30 \%$ in some small sections of weathered material sampled at $20 \mathrm{~m}$ depth in intact but weathered rock beneath the saprolite. These large porosities were measured using X-ray micro-computed tomography. This high porosity in the weathered rock was attributed to microfractures observed to be associated with biotite.

Nanoporosity (measured by neutron scattering) increased from $<1 \%$ in the unweathered rock to $7 \%$ in the saprolite, but much of the increases were in the unconnected portions of the pore network. Therefore, although pore opening was occurring, precipitation during weathering was presumably impacting the pore network connectivity. The dominant pore size in the unweathered rock analyzed by neutron scattering was $<10 \mathrm{~nm}$ in diameter, but porosity was documented to be present at length scales up to $1 \mathrm{~mm}$ and greater. With weathering, the fraction of pores at length scales from $10 \mathrm{~nm}$ to $100 \mathrm{~mm}$ decreased, either through closure due to precipitation or enlargement out of the range of neutron scattering length scales (Bazilevskaya et al. 2015).

The authors concluded that the greater thickness of the regolith and the reaction front on the metagranite compared to the diabase was due to differences in solute transport during early weathering: WIF allowed solute transport by advection that in turn led to thicker regolith. In contrast, on the nearby diabase (described in the next section), microfracturing was not observed and solute transport was limited to diffusive processes. Numerical modeling of weathering systems also supports the conclusion that fracturing leads to greater regolith thickness and reaction front compared to weathering in a non-fractured system (Fig. 3).

Turkish granodiorite. Our third case example reports porosity estimates as a function of weathering based on methods other than neutron scattering (electron imaging and fluid or gas intrusion techniques). In this example, Tugrul (2004) studied the effect of weathering on pore geometry in granodiorite and basalt (described in the next section) using pycnometer and $\mathrm{Hg}$ porosimetry tests to determine total and connected porosity of variably weathered samples, respectively. The degree of weathering of the samples was classified by strength characteristics and not by geochemical analysis. These authors reported that the primary porosity in the Cavusbasi granodiorite in Istanbul was $\sim 5 \%$ and consisted mostly of microfractures. The total porosity of the weathered samples increased with each stage of alteration and at all length scales analyzed (diameters from 0.01 to $100 \mathrm{~mm}$ ) to a total porosity of $12-16 \%$ in the most weathered samples. These highly weathered samples were described as weathered rock where the majority of microfractures are open and the original texture of the rock is still visible. Showing similar behavior to the Puerto Rico quartz diorite, the weathered samples were not characterized by chemical leaching or mineral dissolution until the later stages of weathering. The effective porosity (4\% in the unweathered rock) also did not increase until the last stage of weathering where it increased to $8 \%$.

California granitic corestones. In our fourth case example-granite corestones weathering in the Bishop Creek Moraines, CA-Rossi and Graham (2010) measured porosity to understand water movement and storage in soil and rock fragments. Porosity of these granite samples was determined by the difference between bulk and particle density measurements made by 3-D laser scanning. Porosity was observed to increase with increasing exposure age of the moraine material (determined by $\mathrm{Cl}-36$ cosmogenic dating). They reported a porosity growth rate of $\sim 0.1 \%$ total porosity per kyr: i.e., porosity increased from $\sim 2 \%$ (with low connectivity) in the youngest samples to $\sim 14 \%$ in samples with weathering ages of $120 \mathrm{ka}$. The porosity increase was attributed to an increased number of pores of dimension $>100 \mathrm{~mm}$ (i.e., pores observed in SEM images) without significant change in the extent of weathering as quantified by bulk chemistry. They concluded that microfracturing was the predominant mechanism driving the early porosity increases. In the oldest samples, porosity was observed 


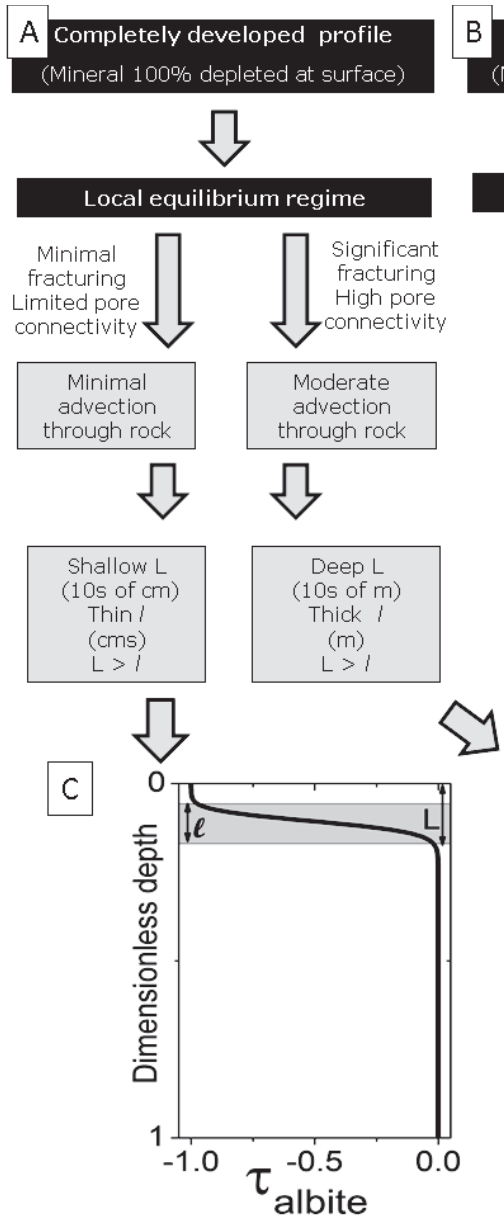

Incompletely developed profile

(Mineral partially depleted at surface)
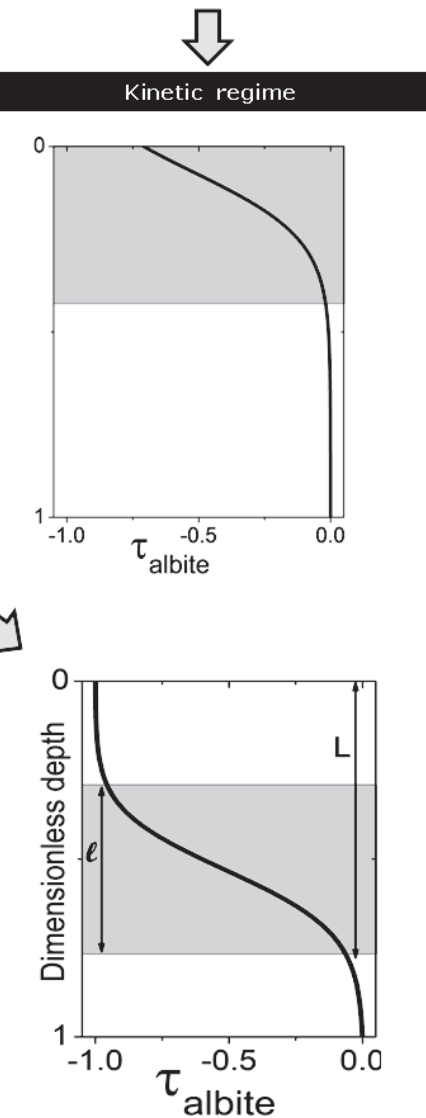

Figure 3. Schematic showing $\tau_{\text {albite }}$ values plotted versus depth for two types of weathering profiles that can be observed at ridgetops where the rate of erosion equals the rate of weathering advance: completely developed profiles (A) and incompletely developed profiles (B). $\tau_{\text {albite }}=0$ when $0 \%$ of the albite has dissolved away and $\tau_{\text {albite }}=-1$ when all the albite has dissolved away. Incompletely developed profiles occur for protoliths that weather so slowly that the system becomes weathering-limited. In this case, the feldspar is still present in the soil at the land surface. Shales can be characterized by incompletely developed weathering profiles (Jin et al. 2010). Completely developed profiles often form on crystalline rocks where weathering is not rate-limiting. More mafic crystalline rocks generally develop thinner reaction fronts $(l$ $=$ reaction front thickness $)$ and regolith $(L=$ regolith thickness) because solute transport across the reaction front is by diffusion. In contrast on felsic rocks, microfracturing in the weathering rock commonly transforms the rock from mass + surface fractal to one or more surface fractals well before disaggregation into saprolite. For any given set of weathering conditions, both $l$ and $L$ therefore tend to grow thicker. In this case the mass + surface fractal transforms to a surface fractal deep in the weathered rock (see Fig. 5). [Used by permission of John Wiley \& Sons, Ltd. from Bazilevskaya EA, Rother G, Mildner DFR, Pavich M, Cole DR, Bhatt MP, Jin L, Steefel C, Brantley SL (2015) How oxidation and dissolution in diabase and granite control porosity during weathering. Earth Surface Processes and Landforms, Vol. 38, Fig 5, p. 854.] 
to increase to a maximum of $\sim 24 \%$ in concert with chemical weathering. They argued that a connected pore network in the matrix adjacent to the microfractures allowed weathering to proceed in these later stages.

Spanish granodiorite. In the fifth case example, Ballesteros et al. (2011) analyzed samples from a 55-60-m deep weathering profile developed on a two-mica Hercynian granodiorite in central Spain using Hg porosimetry, gas adsorption, and density measurement techniques. Porosity increases from $<2 \%$ in the unweathered sample to $>10 \%$ in the upper portion of the profile, $\sim 45 \mathrm{~m}$ from the unweathered bedrock. $\mathrm{Hg}$-porosimetry data was reported to show no measureable pore volume accessible in pore throats $<5 \mathrm{~mm}$ diameter. This was inferred to indicate very low connectivity of small pores in the sample. As the granodiorite weathered, the investigators documented increasing pore connectivity and fluid transport pathways particularly through small pore throats. While no direct evidence of microfracturing was derived from the $\mathrm{Hg}$-porosimetry data, photomicrographs of the weathered granodiorite show microfracturing at micron length scales that likely contribute to the connected pore network.

Japanese granite. The sixth case example is a study of the hydraulic properties of the Tanakami Granite in Japan reported as a function of weathering. This study provides information on porosity development based on macroscale core analyses. Katsura et al. (2009) collected cores of weathered granite in the Kiryu Experimental Watershed and performed infiltration experiments to determine permeability as a function of depth and appearance of rock alteration. Water retention curves from the samples are consistent with the inference that initial alteration of the granite increased the density of micropores (pore diameter $\lesssim 1.5$ $\mathrm{mm}$ ) while the density of macropores only increased in the latest stages of weathering when the rock began to lose most of its internal structure. The development of macropores also corresponded to the largest increases in effective porosity and permeability.

Argentina andesite. Weathering of an andesitic sill in Argentina resulted in complex patterns that include evidence of WIF. Specifically, the andesites show evidence of Liesegang banding, spheroidal weathering fractures (also referred to as onionskin spallation), and hierarchical fracturing (Jamtveit et al. 2011, 2012). Unlike the spheroidal weathering in quartz diorite in Puerto Rico described above where fractures form at outer edges of unweathered corestones, the Argentina andesite was described as showing fractures throughout the weathered zone. Fractures were attributed to precipitates that formed throughout the pore space. Like the Puerto Rico system, weathering fluids were inferred to have entered the unaltered rock ( $8 \%$ porosity) along perpendicular joints formed prior to weathering. The porosity, investigated by Jamtveit et al. (2011) with porosimetry and X-ray microtomography, consists of pores that are either small $(<10 \mu \mathrm{m})$ or relatively large $(10-300 \mu \mathrm{m})$. The larger pores are subtended by very narrow pore throats observed in the range of 20-200 $\mathrm{nm}$. The authors argue that high solubilities are maintained within the small pore throats because of pore-size-related solubility effects (Emmanuel et al. 2015, this volume). These solubilities were inferred to have driven transport of solutes into the larger pores where secondary minerals precipitated. Specifically, the authors argue that dissolution of actinolite + ilmenite + plagioclase in the oxidizing, C-containing meteoric fluids caused precipitation of quartz, calcite, and ferrihydrite.

Jamtveit et al. (2011) emphasize that weathering in the andesites is autocatalytic because of the production of protons during Fe oxidation. The precipitates are localized in the Liesegang bands that are spaced at $2-5 \mathrm{~mm}$. Based on a textural argument, they propose that the rate and position of ring formation are controlled by feedbacks between dissolution localized in pore throats and supersaturation that drives nucleation in the large pores: between the bands, the nucleation barrier is not crossed and no precipitates form. As a result, large pores fill with precipitates, while small pores remain precipitate-free. He and $\mathrm{Hg}$ injection, used to measure porosity, showed that porosity remains high in the andesites, largely because precipitation also causes dilation of the rock at grain boundaries around the larger pores. After 5 to 10 Liesegang 
bands form, the rock tends to fracture spheroidally to form a rindlet. Repetition of these ongoing processes creates well banded and fractured corestones. In addition to banding and onionskin fracturing, an additional phenomenon, hierarchical fracturing, was also identified to occur. Hierarchical fracturing of corestones into smaller fragments was attributed to stress buildups due to weathering.

\section{Weathering of mafic rocks}

In this section we review the available literature on porosity changes with incipient weathering on intermediate to mafic rocks: basalt, basaltic-andesite, and diabase reported in five separate studies. The basalt, basaltic-andesite, and diabase in three of these studies are comprised mainly of plagioclase and augite with little to no olivine, while the andesite examples contain plagioclase and hornblende or actinolite with other minor phases. In general, these rocks are more $\mathrm{Mg}$ and Fe rich (more mafic) than the rocks described in the previous section. In contrast to the felsic rocks described above, WIF is less common on these rocks.

Costa Rica basaltic andesite. Navarre-Sitchler et al. (2009, 2013) analyzed porosity growth with incipient weathering in weathering rinds on basaltic andesite clasts from Costa Rica using neutron scattering and X-ray computed tomography. The clasts, comprised of plagioclase phenocrysts in a plagioclase and augite matrix, were deposited in alluvial terraces during periods of marine highstands ranging from $\sim 50 \mathrm{k}$ to $250 \mathrm{k}$ years ago (Sak et al. 2004). Weathering of the primary minerals in the basaltic andesite to secondary Fe and $\mathrm{Al}$ oxides occurs over a narrow $(\sim 4 \mathrm{~mm})$ reaction front that was imaged in thin sections. Neutrons were scattered from sections cut across the narrow reaction front between the core and weathering rind of three clasts. By situating a screen with a slit for neutron passage in front of the rock section and moving it between neutron scattering measurements, Navarre-Sitchler et al. (2013) measured scattering intensity as a function of distance from the unaltered core of the clast. As expected, the intensity of scattering was observed to increase with distance from the core. Total porosity in these samples (combined porosity measured with neutron scattering and X-ray computed tomography) was observed to increase from $\sim 3 \%$ to $>30 \%$ across that narrow zone and the abundances of the weathering primary minerals (e.g., plagioclase, pyroxene) were observed to decrease from parent concentration to near $0 \%$. Pores in the unweathered basalt were observed to mostly be $<100 \mathrm{~nm}$ in diameter and were observed primarily along grain boundaries and at triple grain junctions. As the basalt weathers, these pores were observed to increase in size and intra-grain porosity with diameters $>100 \mathrm{~nm}$ developed as minerals dissolved in heterogeneous patterns (Fig. 4). The connectivity of porosity was observed to be very low in the unweathered basalt and nanoporosity was observed to be important in the connecting of larger pores. Effective porosity (the porosity contained in a connected pore network) increased with weathering at all analyzed length scales once the total porosity increased to $>9 \%$ (Navarre-Sitchler et al. 2009). The increases in total and connected porosity were inferred to promote important feedbacks in solute transport through the weathered material related to mineral dissolution and weathering rind growth (Navarre-Sitchler et al. 2011).

Volcaniclastic sedimentary rocks in Puerto Rico. Like in the Costa Rica basaltic andesites, no evidence of WIF was commonly observed in a set of weathered andesitic corestones from the volcaniclastic sedimentary rocks of the Fajardo formation in the Bisley watershed in Puerto Rico (Buss, H., pers. comm.). These corestones had about $8 \pm 4 \%$ total porosity (for pores $<10 \mu \mathrm{m}$ ), and they generally remained angular during weathering (Buss et al. 2013). The porosities of two corestones were analyzed with neutron scattering and described by Buss et al. (2013). These samples are more evolved than the basalts from Costa Rica or Turkey, with plagioclase phenocrysts in a quartz and alkali feldspar matrix with minor amphibole content but no biotite. When exposed at the surface or in samples recovered from drill cores, corestones were observed to be characterized by weathering rinds that are usually 


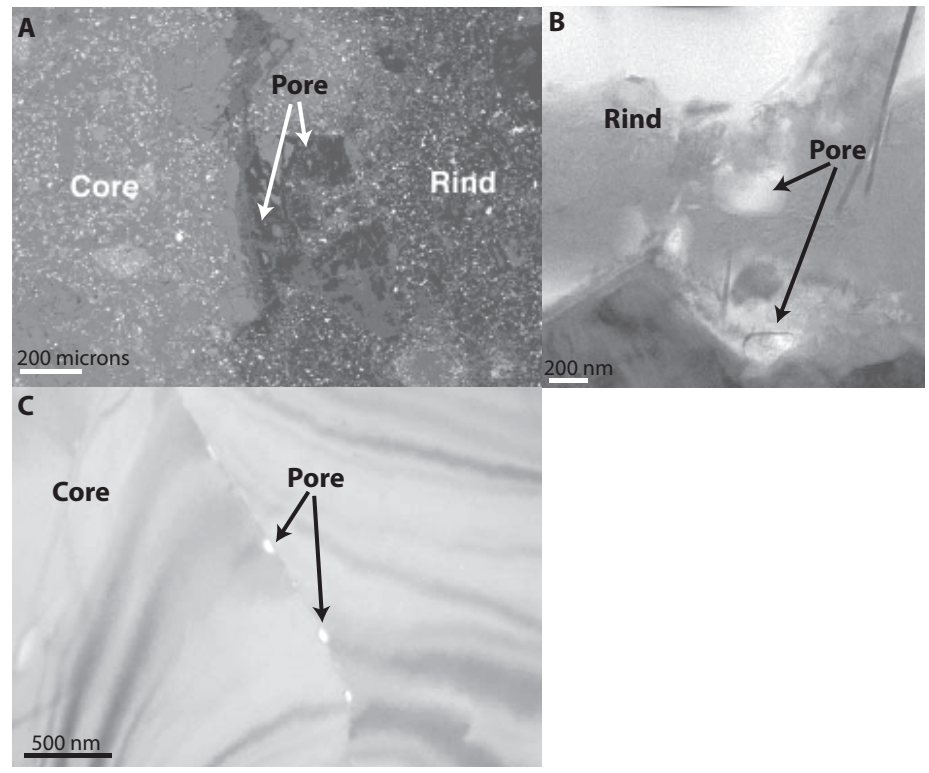

Figure 4. Scanning electron microscope (A) and transmission electron microscope (B, rind and C, core) of weathered basalt clasts from Costa Rica. Pores along grain boundaries (C) enlarge and connect during weathering and promote additional mineral dissolution that leads to $\mathrm{nm}$ and $\mathrm{mm}$ scale pores in heterogeneous patterns at the core rind interface $(\mathrm{A})$ and in the rind $(\mathrm{C})$.

millimeters in thickness. When measured with neutron scattering, the nanoporosity increased slightly with incipient weathering from $<1$ to $2-4 \%$ over a distance of $\sim 4 \mathrm{~mm}$ across the rind. In addition, Fe was enriched and $\mathrm{Ca}$ and $\mathrm{K}$ depleted in the rind compared to $\mathrm{Al}$. The rind material typically reached thicknesses no greater than $1 \mathrm{~cm}$ : this observation is consistent with significant increases in porosity in rind material that allowed spalling off from the corestones. Such thin reaction fronts and rinds on corestones are considered diagnostic of solute transport by diffusion (Navarre-Sitchler et al. 2009, 2011, 2013; Ma et al. 2011; Lebedeva and Brantley 2013).

Virginia Piedmont diabase. Samples from a diabase in the Piedmont region of Virginia (USA) were analyzed with neutron scattering, X-ray computed tomography, and microscopy to evaluate porosity development with weathering (Bazilevskaya et al. 2015). Once again, microfracturing was not observed. The mineralogy of the diabase was dominantly plagioclase and pyroxene. Porosity in the diabase increased from $<2 \%$ in the unweathered diabase to a maximum of $\sim 25 \%$ in the saprolite. In the unweathered rock, most of the porosity was comprised of nanoporosity (diameters $<1 \mathrm{~mm}$ ). Approximately half of the nanoporosity was in a connected network with dominant pore dimensions from 10-20 nm with additional contributions from pores in the $30-70 \mathrm{~nm}$ diameter range. Neither the total (connected + unconnected) nor the connected nanoporosity increased significantly with weathering. However, pore size distributions constructed from neutron scatter data show the nanoporosity that developed was in the $100-500 \mathrm{~nm}$ diameter range. Most of the porosity increases were in pores $>1 \mathrm{~mm}$ diameter, the size range analyzed with X-ray computed tomography.

Using SEM analysis, Brantley et al. (2013b) observed that the first reaction in the diabase was dissolution of $\mathrm{Fe}(\mathrm{II})$-containing pyroxene lamellae without any observable $\mathrm{Fe}(\mathrm{III})$-oxide precipitation (Bazilevskaya et al. 2015). This phenomenon correlated with unusual patterns of 
neutron scattering that exhibited non-isotropic scattering targets showing azimuthal orientations of high scattering intensity. These patterns were inferred to document the dissolution of thin, Fe-containing lamellae in the pyroxenes, probably below the water table.

Turkish basalt. Results from pycnometry and $\mathrm{Hg}$-porosimetry analysis of samples from the Hasanseyh Basalt Formation in Turkey also reveal patterns of porosity growth during incipient basalt weathering that were not characterized by WIF (Tugrul 2004). These samples are similar petrologically to the Costa Rica basalts with plagioclase phenocrysts embedded in a plagioclase and augite matrix. Analysis by $\mathrm{Hg}$-porosimetry revealed that pores in the unweathered basalt are mostly accessible through pore throats $<10 \mu \mathrm{m}$. As porosity increases with weathering, the pore throats associated with that porosity are characterized by diameters $<10 \mu \mathrm{m}$, with many $<10 \mathrm{~nm}$. The authors attribute narrow pore throats in these samples to mineral neoformation in pore spaces, similar to those observed in andesite weathering by Mulyanto and Stoopes (2003). It is likely that the development of narrow pore throats leads to similar effects related to effective porosity during weathering as observed in the Costa Rica basalts (Navarre-Sitchler et al. 2009). Specifically, as porosity increases with incipient weathering, the effective (connected) porosity remains roughly constant until total porosity is $>8 \%$. In the basalt studies by Tugrul (2004), this marked increase in effective porosity does not occur until the sample had weathered enough to be broken apart by hand (weathering category IV as defined in that paper). This relationship between total and effective porosity was shown to have important implications for solute transport through weathered basaltic andesite rocks by Navarre-Sitchler et al. (2009).

\section{LINKING FRACTAL SCALING AND PORE-SCALE OBSERVATIONS TO WEATHERING MECHANISMS}

Brantley et al. (2013b) recently argued that the ratio of ferrous oxides to base cation oxides (i.e., $\mathrm{FeO}$ concentration / the sum of the concentrations of $\mathrm{Na}_{2} \mathrm{O}, \mathrm{K}_{2} \mathrm{O}, \mathrm{CaO}$, and $\mathrm{MgO}$ ) in protolith may be a predictor of whether WIF occurs (Brantley et al., 2013b). Here, the term WIF is restricted the fracturing driven by chemical weathering, and does not include fracturing driven by freeze-thaw, root pressure, or other such processes. In this ratio of $\mathrm{FeO}$ to base cation oxides, the numerator and denominator summarize the relative capacity of the rock to consume oxygen versus the capacity to consume carbon dioxide during weathering, respectively. In rocks with low $\mathrm{FeO}$ concentrations, oxygen may not be consumed at shallow depths, and oxidation may therefore be the deepest weathering reaction. When oxidation leads to reaction products with larger volume than reactants, as inferred for biotite oxidation, the expansion is likely to crack the rock and promote infiltration of meteoric fluids. For example, the volume expansion that occurs during oxidation of biotite has long been well known (Jackson 1840; Eggler et al. 1969; Graham et al. 2010; Rossi and Graham 2010). Thus, for felsic rocks that contain biotite, it may be common that deep oxidation causes WIF that promotes deep infiltration of fluids (Buss et al. 2008; Bazilevskaya et al. 2013, 2015; Navarre-Sitchler et al. 2013).

In contrast, Brantley et al. (2013b) argue that for mafic rocks with more capacity to consume oxygen (i.e., high $\mathrm{FeO}$ content) than $\mathrm{CO}_{2}$ (i.e., sum of the base cation oxide concentrations), the high content of ferrous iron may deplete weathering fluids in $\mathrm{O}_{2}$ at depth so that the deepest weathering reaction is $\mathrm{CO}_{2}$ - rather than $\mathrm{O}_{2}$-promoted. Without a deep oxidation reaction, the rock may not microfracture. Deep porosity that grows during weathering is therefore developed exclusively though dissolution of minerals (Fig. 4). Without significant increases in effective porosity from microfracturing to create a connected pore network, thin regolith and thin reaction fronts may develop as described for the Costa Rica basaltic andesites (NavarreSitchler et al. 2009), the Virginia diabase (Bazilevskaya et al., 2013), and the Hasanseyh Basalt (Tugrul 2004). 
It is interesting to note that these different weathering mechanisms correlate with differences in the transformations of the mass + surface fractals during weathering. For example, Bazilevskaya et al. (2013) showed that the mass + surface fractal that comprises the unweathered granitic rock in the Piedmont of Virginia transforms during weathering to a surface fractal at $20 \mathrm{~m}$ of depth (e.g., Fig. 5, left) where biotite oxidation commences. In contrast to that biotitecontaining rock, in the nearby Virginia diabase, the deepest reaction is non-oxidative dissolution of Fe-containing pyroxene. This reaction occurs at a depth of only a few meters beneath the land surface. Therefore, the pore network in the weathered diabase rock was observed to remain a mass + surface fractal until disaggregation into saprolite (Fig. 5, right).
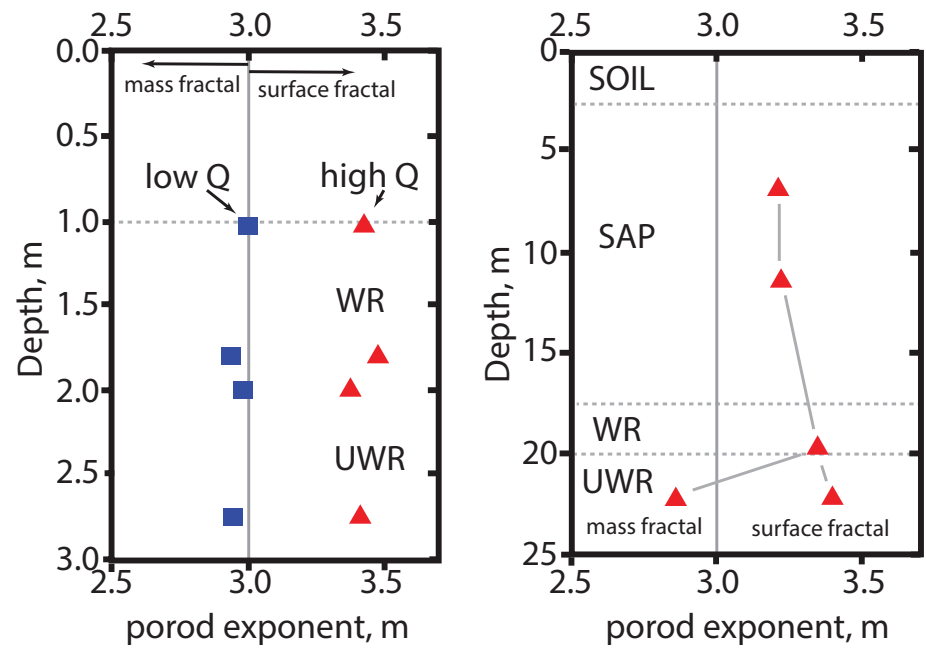

Figure 5. Plots of the values of Porod exponents versus depth plots for diabase (left) and metamorphosed granitic rock (right) weathering in the Piedmont of Virginia. Depth axis shows depth below the mineralorganic soil interface $(\mathrm{SOIL}=$ bioturbated soil, $\mathrm{SAP}=$ saprolite, $\mathrm{WR}=$ cohesive rock showing visual signs of weathering, UWR = cohesive rock showing little to no weathering features). The granitic rock transforms from a mass + surface fractal to a surface fractal deeper than $20 \mathrm{~m}$ depth, where biotite oxidation initiates in weathered rock. In contrast, the diabase never transforms to a surface fractal in the weathered rock. [Used by permission of Soil Science Society of America from Bazilevskaya EA, Rother G, Mildner DFR, Pavich M, Cole DR, Bhatt MP, Jin L, Steefel C, Brantley SL (2015) How oxidation and dissolution in diabase and granite control porosity during weathering. Soil Science Society of America Journal, Vol. 79, Fig. 7b, p. 858.]

Retention of the mass + surface fractal during weathering of still intact rock as observed in the diabase may therefore be a signature of a rock weathering without WIF where solute transport is dominated by diffusion. In contrast, transformation of intact rock porosity to a surface fractal such as in the granitic rocks may be diagnostic of WIF. This comparison between the Virginia diabase and metagranite is similar to the fractal characteristics for basalt and quartz diorite shown in Figure 6 (data from Navarre-Sitchler et al. 2013). On the left, neutron scattering data are summarized for the clast of basaltic andesite that weathered in a fluvial terrace in Costa Rica for 125,000 y (see earlier section). In contrast, scattering data are summarized for the quartz diorite weathering in Puerto Rico on the right of Figure 6. The increases in nanoporosity and associated surface area during weathering are accompanied by a large depletion in plagioclase in the basaltic andesite but not in the quartz diorite (compare the plots of $\tau_{\mathrm{Ca}}$ in Fig. 6). Both the basaltic andesite and the quartz diorite contain internal 
a - Costa Rica Basalt

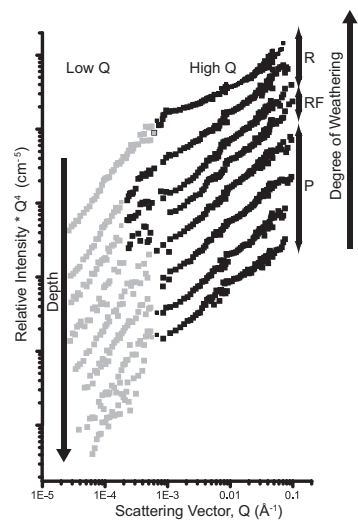

Slope

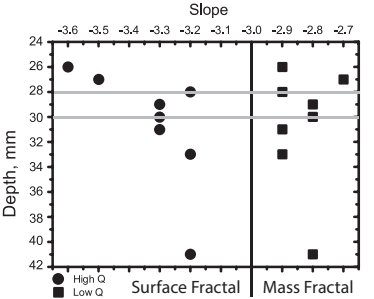

b - Puerto Rico Granite
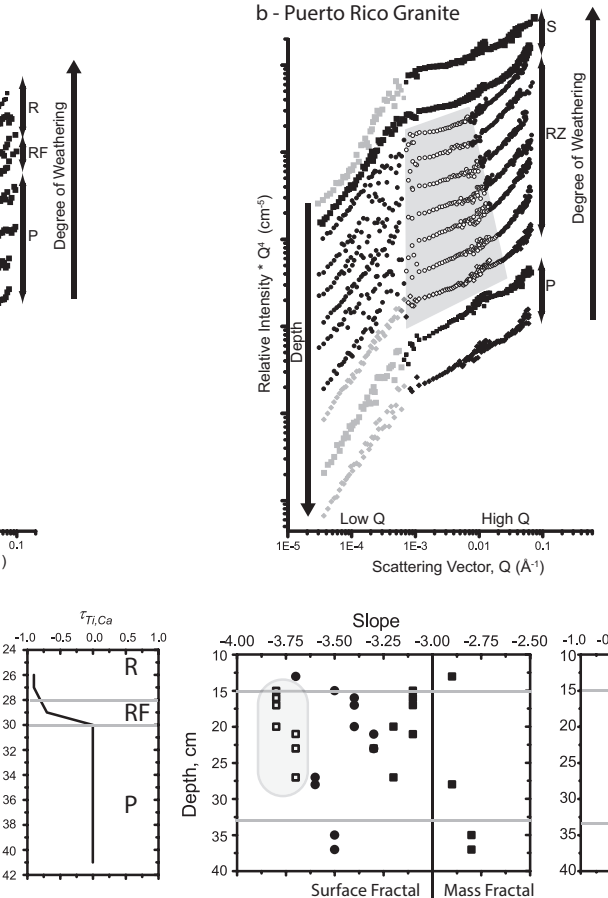

Slope

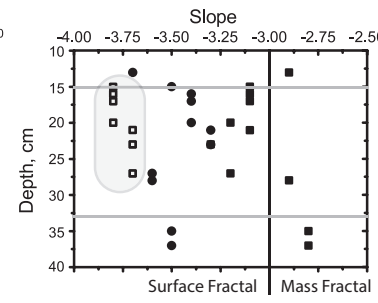

$\tau_{T, \mathrm{Ca}}$

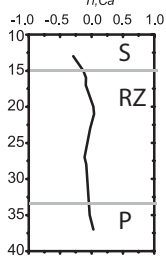

Figure 6. $\log \left(I \times Q^{4}\right)$ versus $\log Q$ (i.e., Porod) plots for Costa Rica basaltic andesite (a) and Puerto Rico quartz diorite (b). Porod plots are stacked so that distance from parent $(\mathrm{P})$ increases upward into the rind (R) or saprolite (S) for (a) basaltic andesite and (b) quartz diorite, respectively. The reaction front is labeled RF for the basalt and RZ for rindlet zone in the quartz diorite. Data fit with a surface fractal are shown in black squares and data fit with a mass fractal are shown as grey squares on the Porod plots. In the lower graphs, the slope of the high- $Q$ data (plotted as squares) and low- $Q$ data (plotted as circles) indicate the mass and surface fractal behaviors of the pore networks as a function of depth and weathering progress. Note that in (b) a new set of features is indicated by the region of shallow slope (hatched) in the RZ, plotted as open squares on the graph. This region is attributed to scattering from smooth surfaces on micro-cracks that develop during weathering. Portions of scattering curves that are non-linear (not fit to fractal model) are shown in open squares. $\tau_{\mathrm{Ca}}$ values plotted versus depth for each of the systems show depletion of $\mathrm{Ca}$ through plagioclase dissolution across the weathering front in the basalt, but little depletion of $\mathrm{Ca}$ in the quartz diorite.

porosity that is characterized by a mass + surface fractal: $D_{m}=2.9$ or 2.8 and $D_{s}=2.7$ or 2.5 before weathering (Navarre-Sitchler et al. 2013). The delineation between the mass and surface fractals in both rocks is approximately $1 \mu \mathrm{m}$. As weathering proceeds across the plagioclase reaction front, the mass + surface fractal is retained in the basaltic andesite (Fig. 6a) but is transformed in the quartz diorite to multiple surface fractals, including a surface fractal region at length scales from 60 to $600 \mathrm{~nm}$ with $\mathrm{D}_{\mathrm{s}}$ ranging from 2.2-2.3 (Fig. 6b) attributed to relatively smooth surfaces of microfractures. This transformation to surface fractals is accompanied by only minor change in specific surface area and porosity until late in the transformation of rock to saprolite (Fig. 7).

Many lines of evidence document that solute transport during weathering of the basaltic andesite clasts is due to diffusion (Navarre-Sitchler et al. 2009, 2011). For example, a decrease 
A-Basaltic Andesite

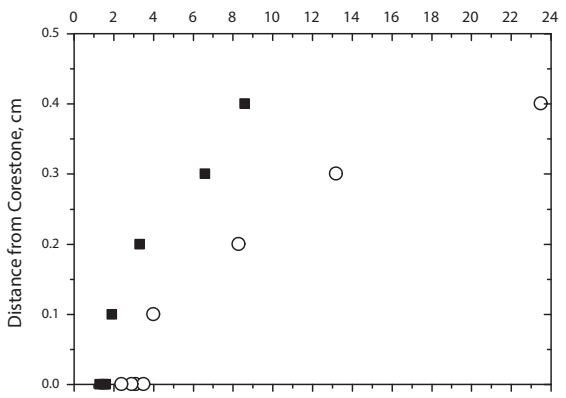

B-Quartz Diorite

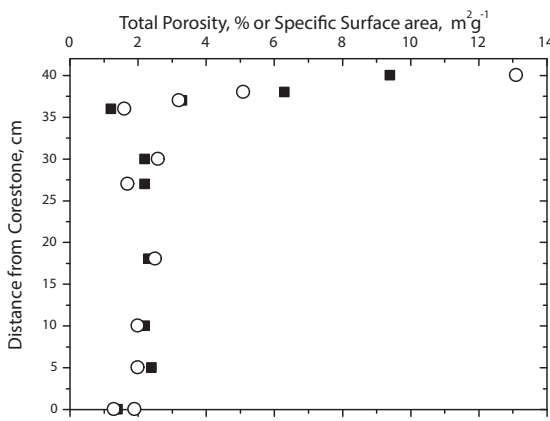

Figure 7. Plots showing the variation in total porosity (closed squares) and specific surface area (open circles) for sample locations within the plagioclase reaction front in the weathering basaltic andesite (A) and quartz diorite (B) shown in Figure 6. In each case, 0 represents the interface between weathered and unweathered material, and weathering intensity increases as distance increases. Between 6 and $37 \mathrm{~cm}$ in (B), the rock has spheroidally fractured into centimeter-thick rindlets. Total porosity and specific surface area were calculated using PRINSAS (Hinde 2004). The surface area does not include contributions from pores with radius larger than $\sim 30 \mathrm{~mm}$. [Used by permission of Elsevier from Navarre-Sitchler AK, Cole D, Rother G, Jin L, Buss HL, Brantley SL (2013) Porosity and surface area evolution during weathering of two igneous rocks. Geochimica et Cosmochimica Acta, Vol. 109, Fig. 5, p. 408.]

in the surface fractal dimension across the reaction front in the basaltic andesite is consistent with the internal porosity becoming less space-filling as the reaction proceeds. Smoothing of mineral surfaces during weathering is generally associated with transport limitation and is thus consistent with diffusion as the solute transport mechanism. In contrast, the transformation of mass + surface fractal to multiple surface fractals during spheroidal weathering is accompanied by precipitation of $\mathrm{Fe}$ and $\mathrm{Mn}$ in some rindlets in the quartz diorite, both of which are consistent with infiltration of meteoric fluids into fractures. The fracturing is inferred to break apart the rock into subzones that are still limited by diffusion of solutes (like the basaltic andesite). However, these subzones become increasingly smaller as microfracturing proceeds. The difference in solute transport through the reaction front-diffusion for the non-fractured basaltic andesite versus advection in the spheroidally weathered felsic rock-is considered the explanation for the orders of magnitude difference in weathering advance rates between the two rock types: 0.24 versus $100 \mathrm{~mm} \mathrm{kyr}^{-1}$, respectively (Fletcher et al. 2006; Pelt et al. 2008). Like the Piedmont rocks, the difference in mechanism of solute transport for the andesitic basalt and the quartz diorite is documented in the fractal dimensions during weathering.

\section{SUMMARY}

In this article we have reviewed the relatively few papers that have been published concerning nano- and micro-scale porosity in incipiently weathering crystalline rocks. Growth of such porosity is diagnostic of the very first stages of regolith formation. To date, few models of porosity formation are available to quantify how fast regolith forms and what environmental or lithologic variables control the rate. For example, the intrinsic dissolution rates of many $\mathrm{Fe}(\mathrm{II})$ - and $\mathrm{Mg}$-containing minerals and the more calcic plagioclases in mafic rocks are faster than the equivalent $\mathrm{Fe}$ - and $\mathrm{Mg}$-poor minerals and more sodic plagioclase in felsic rocks (Bandstra et al. 2008). While some might predict thicker regolith on rocks with faster mineral reaction rates, in general the regolith thickness and reaction front thickness on mafic rocks are thinner than on felsic rocks when developed at ridgetops under similar climate (Bazilevskaya 
et al. 2013; Fig. 1). The observations indicate that chemical weathering cannot be surface reaction (kinetically) controlled alone. It was proposed in the case of the Costa Rican basaltic andesites that the rate was controlled by the rate of porosity generation at the grain (micron) scale (i.e., local-scale surface reaction control leading to enhancement of transport rates within the weathering front). This would suggest that basalts should weather faster, expect for the fact that fracturing intervenes in the case of granitic weathering.

The presence or absence of fracturing during weathering may explain why regolith developed on mafic rocks at ridgetops tends to be thinner than regolith on granitic rocks when other variables are held constant. We have shown several examples where felsic rocks fracture during weathering but mafic have lower occurrences of weathering induced fracturing (WIF). In the felsic rocks the mass + surface fractal that comprises the protolith transforms to one or more surface fractals due to this microfracturing associated with biotite in felsic rocks. This WIF then allows infiltration of advecting meteoric fluids, which in turn widens the reaction front and contributes to formation of thicker regolith (Bazilevskaya et al. 2013; Brantley et al. 2014). Thus weathering of granitic material tends to develop thicker reaction fronts and thicker regolith for a given set of conditions. In contrast, for mafic compositions-perhaps especially those that do not contain biotite-the mass + surface fractal that comprises the protolith is maintained throughout much of the weathering, and the main solute transport mechanism is diffusion. In mafic rocks that weather without WIF, solutes are transported into the reacting low-porosity rock mainly by diffusion, and the reaction front and the regolith that develops tends to be thinner.

Even though several of the studies summarized here for incipient porosity development did not report WIF in mafic rocks, WIF sometimes occurs in the more $\mathrm{Fe}$ - and $\mathrm{Mg}$-rich rocks (e.g., Chatterjee and Raymahashay 1998; Patino et al. 2003; Røyne et al. 2008; Hausrath et al. 2011). It remains to be explained why WIF occurs in some cases but not in others. Presence or absence of biotite may be part of the answer, but a one-to-one correspondence between the presence of biotite and the observation of WIF has not been documented. Another possible explanation is that WIF may be controlled not only by the reduction and acid-neutralizing capacity of the protolith, but also by the relative concentrations of $\mathrm{O}_{2}$ and $\mathrm{CO}_{2}$ in the soil atmosphere (Brantley et al. 2013b). Furthermore, many different mechanisms of WIF have also been proposed (Bisdom et al. 1967; Ollier 1971; Chatterjee and Raymahashay 1998; Fletcher et al. 2006; Jamtveit et al. 2011) and more work is needed to test and understand these and other mechanisms driving fracturing during weathering. A full understanding of regolith formation will only be possible when we can quantitatively describe the changes in porosity and surface area at the pore scale that occur during weathering, especially deep in the Critical Zone.

\section{ACKNOWLEDGMENTS}

The small-angle neutron scattering at the National Institute of Standards and Technology was supported in part by the National Science Foundation under Agreement No DMR-0944772. S. Brantley acknowledges DOE OBES funding DE-FG02-OSER15675 for work using neutron scattering and NSF Critical Zone Observatory Funding for work in the Luquillo Critical Zone Observatory. We thank T. Clark and M. Yashinski at Material Characterization Laboratory at the Pennsylvania State University for FIB-SEM. We thank the Appalachian Basin Black Shales Group at the Pennsylvania State University and PA Topographic and Geologic Survey for providing shale samples. The small-angle neutron scattering at the National Institute of Standards and Technology was supported in part by the National Science Foundation under Agreement No DMR-0944772. S. Brantley acknowledges NSF grant OCE 11-40159 for support for working on Marcellus shale, DOE OBES funding DE-FG02-OSER15675 for work on porosity using neutron scattering. Work by G. Rother was supported by the U.S. Department of Energy, Office 
of Science, Basic Energy Sciences, Chemical Sciences, Geosciences, and Biosciences Division. Research was sponsored by the Laboratory Directed Research and Development Program of Oak Ridge National Laboratory, managed by UT-Battelle, LLC, for the U. S. Department of Energy. The identification of commercial instruments in this paper does not imply recommendation or endorsement by the National Institute of Standards and Technology, nor does it imply that the equipment used are necessarily the best available for the purpose. We would like to thank Carl Steefel and Anja Røyne for their very helpful reviews of this chapter.

\section{REFERENCES}

Aharonov E, Rothman DH (1996) Growth of correlated pore-scale structures in sedimentary rocks: A dynamical model. J Geophys Res-Solid Earth 101:2973-2987

Amundson R (2004) Soil formation. In: Treatise in Geochemistry: Surface and Ground Water, Weathering, and Soils. Drever JI (ed) Elsevier Pergamon, Amsterdam, p 1-35

Anderson SP, Dietrich WE, Brimhall GH (2002) Weathering profiles, mass-balance analysis, and rates of solute loss: Linkages between weathering and erosion in a small, steep catchment. Geol Soc Am Bull 114:1143-1158

Anderson SP, Anderson RS, Hinckley E-LS, Kelly P, Blum A (2011) Exploring weathering and regolith transport controls on critical zone development with models and natural experiments. Appl Geochem 26:S3-S5

Anovitz LM, Cole DR (2015) Analysis of porosity and pore structures. Rev Mineral Geochem 80:61-164

Anovitz LM, Lynn GW, Cole DR, Rother G, Allard LF, Hamilton WA, Porcar L, Kim MH (2009) A new approach to quantification of metamorphism using ultra-small and small angle neutron scattering. Geochim Cosmochim Acta 73:7303-7324

Anovitz LM, Cole DR, Rother G, Allard LF, Jackson AJ, Littrell KC (2013) Diagenetic changes in macro- to nano-scale porosity in the St Peter Sandstone: An (ultra) small angle neutron scattering and backscattered electron imaging analysis. Geochim Cosmochim Acta 102:280-305

Balleseros E, Garcia Talegon J, Inigi Inigo AC, Gonzalez Sanchez M, Herrero Fernandez H (2011) Importance of porosity and transfer of matter in the rock weathering processes: two examples in central Spain. Environmental Earth Sciences 64:1741-1754

Bandstra J, Buss HL, Campen RK, Liermann LJ, Moore J, Hausrath E, Navarre-Sitchler AK, Jang J-H, Brantley SL (2008) Appendix: Compilation of Mineral Dissolution Rates. In: Brantley SL, Kubicki JD, White AF (eds) Kinetics of Water-Rock Interaction. Springer, New York, p 735-822

Bazilevskaya EA, Lebedeva M, Pavich M, Rother G, Parkinson D, Cole DR, Brantley SL (2013) Where fast weathering creates thin regolith and slow weathering creates thick regolith Earth Surf Process Landf 38:847-858

Bazilevskaya EA, Rother G, Mildner DFR, Pavich M, Cole DR, Bhatt MP, Jin L, Steefel C, Brantley SL (2015) How oxidation and dissolution in diabase and granite control porosity during weathering. Soil Sci Soc Am J 79:55-73

Berner RA (1978) Rate control of mineral dissolution under Earth surface conditions. Am J Sci 278:1235-1252

Bisdom EBA (1967) The role of micro-crack systems in the spheroidal weathering of an intrusive granite in Galicia (NW Spain). Geologie en Mijnbouw 46:333-340

Blum JD, Erel Y, Brown K (1994) (87)Sr/(86)Sr ratios of Sierra Nevada stream waters: Implications for relative mineral weathering rates. Geochim Cosmochim Acta 58:5019-5025

Brantley SL, Lebedeva M (2011) Learning to read the chemistry of regolith to understand the critical zone. Ann Rev Earth Planet Sci 39:387-416

Brantley SL, Bandstra J, Moore J, White AF (2008) Modelling chemical depletion profiles in regolith. Geoderma 145:494-504

Brantley SL, Holleran M, Jin L, Bazilevskaya EA (2013a) Probing deep weathering in the Shale Hills Critical Zone Observatory, Pennsylvania (USA): the hypothesis of nested chemical reaction fronts in the subsurface. Earth Surf Process Landf 38:1280-1807

Brantley SL, Lebedeva M, Bazilevskaya EA (2013b) Relating weathering fronts for acid neutralization and oxidation to $\mathrm{pCO}_{2}$ and $\mathrm{pO}_{2}$, In: Treatise of Geochemistry, The Atmosphere-History, 2nd edition. Farquhar J, Kasting J, Canfield D (eds) Elsevier, Amsterdam, The Netherlands, p 327-352

Brunauer S, Emmett PH, Teller E (1938) Adsorption of gases in multimolecular layers. J Am Chem Soc 60:309-319

Bricker O, Bowser C, Jones B (2004) Mass balance approach to interpreting weathering reactions in watershed systems. In: Treatise on Geochemistry: Surface and Ground Water, Weathering, and Soils. Drever JI (ed), Elsevier, Amsterdam, p 119-132 
Burke BC, Heimsath AM, White AF (2007) Coupling chemical weathering with soil production across soilmantled landscapes. Earth Surf Process Landf 32:853-873

Buss HL, Sak P, Webb RM, Brantley S (2008) Weathering of the Rio Blanco quartz diorite, Luquillo Mountains, Puerto Rico: Coupling oxidation, dissolution and fracturing. Geochim Cosmochim Acta 72:4488-4507

Buss HL, Brantley SL, Scatena FN, Bazilevskaya EA, Blum A, Schultz MJ, White AF, Rother G, Cole DR (2013) Probing the deep critical zone beneath the Luquillo Experimental Forest, Puerto Rico. Earth Surf Process Landf 38:1170-1186

Certini G, Campbell CD, Edwards AC (2004) Rock fragments in soil support a different microbial community from the fine earth. Soil Biol Biochem 36:1119-1128

Chatterjee A, Raymahashay BC (1998) Spheroidal weathering of Deccan Basalt: a three-mineral model. Q J Eng Geol 31:175-179

Clow DW, Drever JI (1996) Weathering rates as a function of flow through an alpine soil. Chem Geol 132:131141

Cousin I, Nicoullaud B, Coutadeur C (2003) Influence of rock fragments on the water retention and water percolation in a calcareous soil. Catena 53:97-114

Drever JI, Clow DW (1995) Weathering rates in catchments. Rev Mineral 31:463-481

Eggler DH, Larson EE, Bradley WC (1969) Granites, grusses, and the Sherman erosion surface, southern Laramie Range, Colorado-Wyoming. Am J Sci 267:510-522

Emmanuel S, Anovitz LM, Day-Stirrat RJ (2015) Effects of coupled chemo-mechanical processes on the evolution of pore-size distributions in geological media. Rev Mineral Geochem 80:45-60

Fletcher RC, Buss HL, Brantley SL (2006) A spheroidal weathering model coupling porewater chemistry to soil thicknesses during steady-state denudation. Earth Planet Sci Lett 244:444-457

Gaillardet J, Millot R, Dupre B (2003) Chemical denudation rates of the western Canadian orogenic belt: the Stikine terrane Chem Geol 201:257-279

Graham R, Rossi A, Hubbert K (2010) Rock to regolith conversion: Producing hospitable substrates for terrestrial ecosystems. GSA Today 20:4-9

Graham RC, Guertal WR, Tice KR (1994) The pedologic nature of weathered rock. In: Cremeens DL, Brown RB, Huddleston JH (eds), Whole Regolith Pedology, SSSA Special Publication Number 34, Soil Science Society of America, Madison WI, p 21-40

Gu X, Cole DR, Rother G, Mildner DFR, Brantley SL (2015) Pores in Marcellus Shale: A neutron Scattering and FIB-SEM Study Energy \& Fuels, doi: 101021/acsenergyfuels5b00033

Hausrath E, Navarre-Sitchler A, Sak PB, Williams J, Brantley SL (2011) Soil profiles as indicators of mineral weathering rates and organic interactions for a Pennsylvania diabase. Chem Geol 290:89-100

Hinde AL (2004) PRINSAS - a Windows-based computer program for the processing and interpretation of small-angle scattering data tailored to the analysis of sedimentary rocks. J Appl Crystallogr 37:1020-1024

Hubbert KR, Beyers JL, Graham RC (2001) Roles of weathered bedrock and soil in seasonal water relations of Pinus jeffreyi and Arctostaphylos patula. Can J Forest Res 31:1947-1957

Jackson CT (1840) Report on the geological and agricultural survey of the State of Rhode Island, B. Cranston and Co., Providence, p 327

Jamtveit B, Hammer O (2012) Sculpting of Rocks by Reactive Fluids. Geochem Perspect 1:341-480

Jamtveit B, Kobchenko M, Austrheim H, Malthe-Sørenssen A, Røyne A, Svensen H (2011) Porosity evolution and crystallization-driven fragmentation during weathering of andesite. J Geophys Res 116:B12204

Jin L, Brantley SL (2011) Soil chemistry and shale weathering on a hillslope influenced by convergent hydrologic flow regime at the Susquehanna/Shale Hills Critical Zone Observatory. Appl Geochem 26:S51-S56

Jin L, Ravella RBK, Bierman PR, Heaney P, White T, Brantley SL (2010) Mineral weathering and elemental transport during hillslope evolution at the Susquehanna/Shale Hills Critical Zone Observatory. Geochim Cosmochim Acta 74:3669-3691

Jin L, Rother G, Cole DR, Mildner DFR, Duffy CJ, Brantley SL (2011) Characterization of deep weathering and nanoporosity development in shale - a neutron study. Am Mineral 96:498-512

Jin L, Mathur R, Rother G, Cole DR, Bazilevskaya EA, Williams JZ, Carone A, Brantley SL (2013) Evolution of porosity and geochemistry in Marcellus Formation black shale during weathering. Chem Geol 356:14

Kahle A, Winkler B, Radulescu A, Schreuer (2004) Small-angle neutron scattering study of volcanic rocks. Eur J Mineral 16:407-417

Kang QJ, Lichtner P, Zhang DX (2007) An improved lattice Boltzmann model for multi-component reactive transport in porous media at the pore scale. Water Resour Res 43:W12S14

Katsura S, Kosugi K, Mizutani T, Mizuyama T (2009) Hydraulic properties of variously weathered granitic bedrock in headwater catchments. Vadose Zone J 8:557-573 
Kelemen PB, Matter J, Streit EE, Rudge JF, Curry WB, Blusztian J (2011) Rates and mechanisms of mineral carbonation in peridotite: Natural processes and receipts for enhanced, in situ $\mathrm{CO}_{2}$ capture and storage. Ann Rev Earth Planet Sci 39:545-576

Landrot G, Ajo-Franklin JB, Yang L, Cabrini S, Steefel CI (2012) Measurement of accessible reactive surface area in a sandstone, with application to $\mathrm{CO}_{2}$ mineralization. Chem Geol 318-319:113-125

Lebedeva M, Brantley SL (2013) Exploring geochemical controls on weathering and erosion of convex hillslopes: beyond the empirical regolith production function. Earth Surf Process Landf 38:1793-1807

Li L, Steefel C, Yang L (2008) Scale dependence of mineral dissolution rates within single pores and fractures. Geochim Cosmochim Acta 72:360-377

Li D, Jacobson AJ, McInerney DJ (2013) A reactive-transport model for examining tectonic and climatic controls on chemical weathering and atmospheric $\mathrm{CO}_{2}$ consumption in granitic regolith. Chem Geol 365:30-42

Lichtner P (1988) The quasi-stationary state approximation to coupled mass transport and fluid-rock interaction in a porous medium. Geochim Cosmochim Acta 52:143-165

Lowell S, Shields JE, Thomas MA, Thommes M (2004) Characterization of Porous Solids and Powders: Surface Area, Pore Size and Density. Kluwer Academic Publishers, Dordrecht

Ma L, Jin L, Brantley SL (2011) How mineralogy and slope aspect affect REE release and fractionation during shale weathering in the Susquehannah/Shale Hills Critical Zone Observatory. Chem Geol 290:31-49

Maher K, Chamberlain CP (2014) Hydrologic Regulation of Chemical Weathering and the Geologic Carbon Cycle. Science 343:1502-1504

Merrill GP (1906) A Treatise on Rocks, Rock Weathering, and Soils. MacMillan Inc, New York

Mildner DFR, Rezvani R, Hall PL, Borst RL (1986) Small-angle scattering of shaly rocks with fractal pore interfaces. Appl Phys Lett 48:1314-1316

Molins S (2015) Reactive interfaces in direct numerical simulation of pore scale processes. Rev Mineral Geochem 80:461-481

Molins S, Trebotich D, Steefel C, Shen C (2012) An investigation of the effect of pore scale flow on average geochemical reaction rates using direct numerical simulation. Water Resour Res 48:W03527

Molnar P, Anderson RS, Anderson SP (2007) Tectonics, fracturing of rocks, and erosion. J Geophys Res-Solid Earth 112:1-12

Mulyanto B, Stoops G (2003) Mineral neoformation in pore spaces during alteration and weathering of andesitic rocks in humid tropical Indonesia. Catena 54:385-391

Nahon D (1991) Introduction to the Petrology of Soils and Chemical Weathering. John Wiley \& Sons, New York

Navarre-Sitchler A, Steefel CI, Yang L, Tomutsa L (2009) Evolution of porosity and diffusivity associated with chemical weathering of a basalt clast. J Geophys Res - Earth Surf 114:1-14

Navarre-Sitchler A, Steefel CI, Sak PB, Brantley SL (2011) A reactive-transport model for weathering rind formation on basalt. Geochim Cosmochim Acta 75:7644-7667

Navarre-Sitchler AK, Cole D, Rother G, Jin L, Buss HL, Brantley SL (2013) Porosity and surface area evolution during weathering of two igneous rocks. Geochim Cosmochim Acta 109:400-413

Ollier CD (1971) Causes of spheroidal weathering. Earth-Sci Rev 7:127-141

Ollier CD (1985) Deep weathering, groundwater, and climate. Geografiska Annaler Series A, Phys Geog 70:285-290

Patino LC, Velbel MA, Price JR, Wade JA (2003) Trace element mobility during spheroidal weathering of basalts and andesites in Hawaii and Guatemala. Chem Geol 202:343-364

Pavich M (1986) Process and rates of saprolite production and erosion on a foliated granitic rock of the Virginia Piedmont. In: Colman S, Dethier D (eds), Rates of Chemical Weathering of Rocks and Minerals. Academic Press, London, p 552-590

Pelt E, Chabaux F, Innocent C, Navarre-Sitchler A, Sak P, Brantley S (2008) Uranium-throium chronometry of weathering rinds: Rock alteration rate and paleo-isotopic record of weathering fluids. Earth Planet Sci Lett 276:98-105

Radlinski AP (2006) Small-angle neutron scattering and the microstructure of rocks. Rev Mineral Geochem 63:363-397

Radlinski AP, Radlinska EZ, Agamalian M, Wignall GD, Lindner P, Randl OG (1999) Fractal geometry of rocks. Phys Rev Lett 82:3078-3081

Radlinski AP, Radlinska EZ, Agamalian M, Wignall GD, Lindner P, Randl OG (2000) The fractal microstructure of ancient sedimentary rocks. J Appl Crystallogr 33:860-862

Radlinski AP, Ioannidis MA, Hinde AL, Hainbuchner M, Baron M, Rauch H, Kline SR (2004) Angstromto-millimeter characterization of sedimentary rock microstructure. J Colloid Interface Sci 274:607-612

Rouquerol J, Avnir D, Fairbridge CW, Everett DH, Haynes JH, Pernicone N, Ramsay JDF, Sing KSW, Unger KK (1994) Recommendations for the characterization of porous solids. Pure Appl Chem 66:1739-1758 
Rossi A, Graham RC (2010) Weathering and porosity formation in subsoil granitic clasts, Bishop Creek Moraines, California. Soil Sci Soc Am J 74:172-185

Rother G, Woywod D, Schoen M, Findenegg G H (2004) Confinement effect on the adsorption from a binary liquid system near liquid/liquid phase separation. J Chem Phys 120:11864-11873

Røyne A, Jamtveit B, Mathiesen J, Malthe-Sorenssen A (2008) Controls on rock weathering rates by hierarchical weathering-induced fractures. Earth Planet Sci Lett 275:364-369

Sak PB, Fisher DM, Gardner TW, Murphy K, Brantley SL (2004) Rates of weathering rind formation on Costa Rican basalt. Geochim Cosmochim Acta 68:1453-1472

Schmidt PW (1991) Small-angle scattering studies of disordered, porous and fractal systems. J Appl Crystallogr 24:414-435

Sing KSW, Everett DH, Haul RW, Moscou L Pierotti, RA Rouquerol J, Siemieniewska T (1985) Reporting physisorption data for gas/solid systems with special reference to the determination of surface area and porosity. Pure Appl Chem 57:603-619

Sternberg PD, Anderson MA, Graham RC, Beyers JL, Tice KR (1996) Root distribution and seasonal water status in weathered granitic bedrock under chaparral. Geoderma 72:89-98

Taylor G, Eggleston RA (2001) Regolith Geology and Geomorphology. John Wiley and Sons, Chichester

Teixeira J (1988) Small-angle scattering by fractal systems. J Appl Crystallogr 21:781-785

Thommes M, Cychosz KA (2014) Physical adsorption characterization of nanoporous materials: progress and challenges. Adsorption 20:233-250

Tugrul A (2004) The effect of weathering on pore geometry and compressive strength of selected rock types from Turkey. Eng Geol 75:215-227

Turner BF, Stallard RF, Brantley SL (2003) Investigation of in situ weathering of the quartz diorite bedrock in the Rio Icacos basin, Luquillo Experimental Forest, Puerto Rico. Chem Geol 202:313-341

Twidale CR, Vidal Romani JR (2005) Landforms and geology of granite terrains. AA Balkema Publishers, Leiden, The Netherlands

White AF (2002) Determining mineral weathering rates based on solid and solute weathering gradients and velocities: application to biotite weathering in saprolites. Chem Geol 190:69-89

White AF (2008) Quantitative approaches to characterizing natural chemical weathering rates. In: Brantley SL, Kubicki JD, White AF (Eds), Kinetics of Water Rock Interaction. Springer, New York, p 469-544

Witty JH, Graham RC, Hubbert KR, Doolittle JA, Wald JA (2003) Contributions of water supply from teh weathered bedrock zone to forest soil quality. Geoderma 114:389-400

Wong P-z, Bray AJ (1988) Porod scattering from fractal surfaces. Phys Rev Lett 60:1344-1344

Woywod D, Schemmel S, Rother G, Findenegg GH, Schoen M (2005) Phase behavior and local structure of a binary mixture in pores: Mean-field lattice model calculations for analyzing neutron scattering data. $\mathrm{J}$ Chem Phys 122:124510

Wyrick GG, Borchers JW (1981) Hydrologic effects of stress-relief fracturing in an Appalacian valley, United States Geological Survey. Water-Supply Paper 2177

Zanner CW, Graham RC (2005) Deep regolith: exploring the lower reaches of soil. Geoderma 126:1-3

Zwieniecki MA, Newton M (1996) Seasonal pattern of water depletion from soil-rock profiles in a mediteranean climate in southwestern Oregon. Can J Forest Res 26:1346-1352 